\title{
“Type 1 on Type 2" Diabetes Mellitus: Autoimmune Type 1 Diabetes Superimposed on Established Type 2 Diabetes
}

\author{
Takahiro Suzuki ${ }^{1}$, Kenji Takahashi ${ }^{1}$, Satoshi Miyamoto ${ }^{1}$, Hiroyuki Ueno ${ }^{1}$, \\ Sato Takekawa ${ }^{1}$, Atsushi Yoshida ${ }^{1}$ and Motohiro Fujita ${ }^{2}$
}

\begin{abstract}
Objective To investigate clinical features and pathophysiology of a rare form of new-onset type 1 diabetes mellitus that was superimposed on established type 2 diabetes.

Patients and Methods We retrospectively analyzed 126 consecutive type 2 diabetic patients, who were admitted to the hospital 2 or more times from July 2000 to December 2005 and had been repeatedly examined for islet-associated autoantibodies and insulin secretory capacity over a period of years.

Results We experienced 2 patients in whom autoantibodies including ICA, GADAb, and IA-2Ab were initially all negative, but in whom at least 1 of these antibodies later became positive, whose endogenous insulin secretion decreased, and who eventually reached an insulin-dependent stage. At the time of seroconversion of antibodies, the patients had 15 to 23 years' history of diabetes, and had microvascular complications specific to diabetes mellitus, and before seroconversion insulin secretory capacities were preserved. The patients had HLA types associated with susceptibility to Japanese type 1 diabetes mellitus.

Conclusions Our findings suggest that autoimmune type 1 diabetes mellitus may be superimposed on wellestablished type 2 diabetes.
\end{abstract}

Key words: type 1 diabetes, type 2 diabetes, autoimmune diabetes, islet-associated antibodies, superimpose, type 1 on type 2 diabetes mellitus

(DOI: 10.2169/internalmedicine.46.0282)

\section{Introduction}

Diabetes mellitus is mainly classified into type 1 and type 2 diabetes based on its etiology and pathophysiology, and each type of diabetes has its own unique clinical and etiological features (1). We experienced an elderly patient in 1998 who presented with a long history of type 2 diabetes, whose islet-associated antibodies seroconverted spontaneously, and whose insulin secretory capacity progressively deteriorated, eventually resulting in insulin dependency (2). Hence, type 1 diabetes appeared to have been superimposed on type 2 diabetes, a situation that was not previously considered to occur in an individual. To search for other cases similar to the above case, we analyzed a large number of consecutive type 2 diabetic patients who were admitted to the hospital. We present here those cases expressing rare pathological features consistent with "type 1 on type 2" diabetes mellitus, and we discuss the implications of our findings.

\section{Methods}

Of the total of 1836 type 2 diabetic patients who were admitted to our hospital from July 2000 to December 2005, we retrospectively analyzed the 126 consecutive type 2 diabetic patients who were admitted to the hospital 2 or more times and had been repeatedly examined for islet-associated autoantibodies and endogenous insulin secretion over a period of several years. As standard examinations for newly admitted type 2 diabetic patients, we performed routine biochemical tests, examination for diabetic microvascular com-

${ }^{1}$ Division of Diabetes, Department of Internal Medicine, Kurashiki Central Hospital, Kurashiki and ${ }^{2}$ Fujita Street Clinic, Kurashiki Received for publication May 1, 2007; Accepted for publication August 6, 2007

Correspondence to Dr. Kenji Takahashi, kenjit@kchnet.or.jp 
plications, measurement of islet-associated autoantibodies, including islet cell cytoplasmic antibodies (ICA), glutamic acid decarboxylase antibody (GADAb), and insulinomaassociated protein 2 autoantibody (IA-2Ab), and evaluation of insulin secretory capacity, including urinary C-peptide secretion, serum C-peptide concentration, and glucagonloading test. At the second admission (mainly due to sulfonylurea failure or deteriorated blood glucose control), we examined the autoantibodies and performed C-peptide tests again, as at the first admission. In patients who showed seroconversion for autoantibodies, we checked the HLA patterns.

ICA was measured at our facility by an indirect immunofluorescence test using rat pancreatic sections (3), which has $82 \%$ sensitivity and $99 \%$ specificity (4). GADAb and IA-2Ab were measured at SRL (Japan) using an RIA kit manufactured by RSR Limited (UK) and imported by Cosmic Corporation (Japan) (GADAb, cut-off point $1.3 \mathrm{U} /$ $\mathrm{ml}$, intra-assay $\mathrm{CV}$ value $<17 \%$; IA- $2 \mathrm{Ab}$, cut-off point 0.4 $\mathrm{U} / \mathrm{ml}$, intra-assay $\mathrm{CV}$ value $6 \%$ ).

\section{Results}

Among 126 patients with type 2 diabetes who were repeatedly examined for autoantibodies and insulin secretory capacity, we found 2 cases in which 1 of the 3 autoantibodies tested was seroconverted and insulin secretion deteriorated. We present here the clinical courses and clinical data of these 2 cases.

Case 1: A 67-year-old women was diagnosed with diabetes at the age of 52 years. Her mother had diabetes. She had developed a brain infarction at the age of 59, and was heaviest at $62 \mathrm{~kg}$ (BMI: 28.3) at the age of 61. Since the age of 62 , she had been treated using sulfonylurea (gliclazide). In January 2000 (age: 67), she was admitted to the hospital due to poor glycemic control. At that time, HbAic was $11.8 \%$, and ICA, GADAb, and IA-2Ab were negative. The plasma C-peptide was $1.20 \mathrm{ng} / \mathrm{ml}$ before breakfast and 2.16 $\mathrm{ng} / \mathrm{ml} 2$ hours after breakfast. A glucagon-loading test showed that plasma C-peptide increased by $0.85 \mathrm{ng} / \mathrm{ml}$, and urinary C-peptide was $106 \mu \mathrm{g} /$ day. Accordingly, $0.9 \mathrm{mg}$ of voglibose was added to gliclazide, and premixed human insulin was administered before dinner. However, as glycemic control deteriorated again after 6 months, the oral agents were discontinued and premixed human insulin was commenced twice daily. Although a localized skin insulin allergy appeared, the insulin therapy was continued. In October 2000 (age: 67), she was readmitted to undergo detailed examination. HbA1c was $9.1 \%$ and body weight $60 \mathrm{~kg}$ (BMI: 27.4). Simple diabetic retinopathy was seen in the ocular fundus, and diminished tendon reflexes were noted in both legs. Regarding autoantibodies, ICA and GADAb were negative, but IA-2Ab had become positive $(31.0 \mathrm{U} / \mathrm{ml})$. Plasma C-peptide was $0.0 \mathrm{ng} / \mathrm{ml}$ before and 2 hours after breakfast, a glucagon-loading test showed no increase in plasma C-peptide, and urinary C-peptide was $2 \mu \mathrm{g} /$ day. Sub- sequently, multiple insulin injection therapy with premeal regular insulin and bedtime intermediate-acting (NPH) insulin was started.

Case 2: A 67-year-old man was diagnosed with diabetes at the age of 44 years and was placed on sulfonylurea (glibenclamide) therapy. His mother and older brother had type 2 diabetes. His past medical history was noncontributory. He was heaviest at $65 \mathrm{~kg}$ (BMI: 24.6) at the age of 20. In December 2001 (age: 63), he was admitted due to sulfonylurea failure. HbA1c was $8.5 \%$, and ICA, GADAb, and IA-2Ab were negative. The plasma C-peptide was $0.60 \mathrm{ng} /$ $\mathrm{ml}$ before breakfast and $3.04 \mathrm{ng} / \mathrm{ml} 2$ hours after breakfast. A glucagon-loading test showed that plasma C-peptide increased by $0.89 \mathrm{ng} / \mathrm{ml}$, and urinary C-peptide was $68 \mu \mathrm{g}$ / day. Glibenclamide was discontinued, and premixed human insulin was commenced twice daily. However, as HbA1c increased from 2003, and glycemic control did not improve despite increasing the insulin dose, he was readmitted in March 2005 (age: 67). At that time, HbA1c was 9.5\%, body weight was $55.6 \mathrm{~kg}$, simple diabetic retinopathy was seen in the ocular fundus, reduced tendon reflex and vibratory sensation were noted in the legs, and microalbuminuria was detected. As to autoantibodies, ICA and IA-2Ab were negative, but GADAb had become positive $(6890.0 \mathrm{U} / \mathrm{ml})$. The plasma C-peptide was $0.0 \mathrm{ng} / \mathrm{ml}$ before and 2 hours after breakfast, a glucagon-loading test showed no increase in plasma C-peptide, and urinary C-peptide was $2 \mu \mathrm{g} /$ day. Subsequently, his therapy was changed to a multiple insulin injection method with premeal insulin aspart and bedtime insulin glargine.

Both patients had serum HLA serotype of A24/B54/DR4 and HLA class II genotypes of DRB1*0405-DQB1*0401 or DRB $1^{*} 0901-D Q B 1^{*} 0303$, thus exhibiting disease sensitivity to Japanese type 1 diabetes mellitus (Table 1-a, 1-b).

\section{Discussion}

In our present hospital-based type 2 diabetic population study, 2 new-onset autoimmune type 1 diabetic cases were recognized among the type 2 diabetes group (2/126 patients/ 5 years $=0.32 \%$ per year). The incidence was seen higher than the general incidence of type 1 diabetes mellitus in Japan (about 3 persons per 100,000/year $=0.003 \%$ per year). Full-checking of islet-associated antibodies is usually not done in the ordinary medical practice for diabetes, and our study suggests that if autoantibodies and insulin secretory capacities were repeatedly examined in type 2 diabetic patients in whom deteriorated glycemic control or rapid sulfonylurea failure were recognized, more cases of patients consistent with "type 1 on type 2 " diabetes mellitus could be found.

We also present here a short clinical summary of the first case previously reported by us (2), which was considered a case of type 1 on type 2 diabetes mellitus, with permission of the Japan Diabetes Society.

Fujita's case (2): An 80-year-old woman was diagnosed 
Table 1-a. Laboratory Findings of Case 1

\begin{tabular}{|c|c|c|}
\hline & Jan 2000 & Oct 2000 \\
\hline \multicolumn{3}{|l|}{ Insulin secretory capacity } \\
\hline urinary CPR ( $\mu \mathrm{g} /$ day) (3 days) & $123,106,55$ & $2,3,2$ \\
\hline \multicolumn{3}{|l|}{ serum CPR (ng/ml) } \\
\hline fasting & 1.20 & 0.00 \\
\hline 2 hours after breakfast & 2.16 & 0.00 \\
\hline \multicolumn{3}{|l|}{ glucagon-load CPR (ng/ml) } \\
\hline before & 1.21 & 0.00 \\
\hline $6 \mathrm{~min}$. after load & 2.06 & 0.00 \\
\hline \multicolumn{3}{|l|}{ Islet-associated antibodies } \\
\hline ICA & $<1: 5$ & $<1: 5$ \\
\hline GADAb (U/ml) & $<0.4$ & $<0.4$ \\
\hline $\mathbf{I A - 2 A b}(\mathrm{U} / \mathrm{ml})$ & $<0.4$ & 31.0 \\
\hline \multicolumn{3}{|c|}{ HLA class I , II serotype: A24,-/B48,54/Cw1,-/DR4,14/DQ4,- } \\
\hline HLA DR-DQ genotype: DRB1 $* 0405, * 1$ & $1, * 0502$ & \\
\hline
\end{tabular}

Table 1-b. Laboratory Findings of Case 2

\begin{tabular}{|c|c|c|}
\hline & Dec 2001 & Mar 2005 \\
\hline \multicolumn{3}{|l|}{ Insulin secretory capacity } \\
\hline urinary $\operatorname{CPR}(\mu \mathrm{g} /$ day $)$ & 68 & 2 \\
\hline \multicolumn{3}{|l|}{ serum CPR (ng/ml) } \\
\hline fasting & 0.60 & 0.00 \\
\hline 2 hours after breakfast & 3.04 & 0.00 \\
\hline \multicolumn{3}{|l|}{ glucagon-load CPR (ng/ml) } \\
\hline before & 0.12 & 0.01 \\
\hline $6 \mathrm{~min}$. after load & 1.01 & 0.01 \\
\hline \multicolumn{3}{|l|}{ Islet-associated antibodies } \\
\hline ICA & $<1: 5$ & $<1: 5$ \\
\hline GADAb (U/ml) & $<0.4$ & 6890.0 \\
\hline $\mathbf{I A - 2 A b}(\mathbf{U} / \mathbf{m l})$ & $<0.4$ & $<0.4$ \\
\hline \multicolumn{3}{|c|}{ HLA class I , II serotype: A24,31/B51,54/Cw1,-/DR4,9/DQ3,4 } \\
\hline \multicolumn{3}{|c|}{ HLA DR-DQ genotype: DRB1*0405,*0901/DQB1*0303,*0401 } \\
\hline
\end{tabular}

Table 1-a, 1-b. The results of diabetes-related tests in the present 2 cases are shown. The left column shows the results for the first admission, while the right column shows the results for the second admission. Endogenous insulin secretion and islet autoantibodies were tested. At the second admission, insulin secretory capacity was highly reduced, and seroconversion was seen for one antibody. HLA serotype A24, B54, DR4 and DR9, which are frequently seen in type 1 diabetes, were shown, and HLA class II genotypes DRB1*0405, *0901/DQB1*0303, *0401, are also compatible with Japanese type 1 diabetes. Hence, the patients were both genetically susceptible to type 1 diabetes, but in terms of the clinical course, they had a phenotype of type 2 diabetes mellitus for a long time before seroconversion. Because ICA measured at our facility is not authorized by Juvenile Diabetes Federation (JDF), JDF unit is not available to us for expressing the titer of ICA. Abbreviations: CPR: C-peptide, ICA: islet cell cytoplasmic antibodies, GADAb: glutamic acid decarboxylase antibody, IA-2Ab: insulinoma-associated protein 2 autoantibody 
Table 2. Clinical Summary of the 3 Cases at Development of Type 1 Diabetes Mellitus

\begin{tabular}{|c|c|c|c|}
\hline & Case 1 & Case 2 & Fujita's case (2) \\
\hline Age at diagnosis of diabetes (years) & 52 & 44 & 66 \\
\hline Age at Seroconversion (years) & 67 & 67 & 80 \\
\hline \multicolumn{4}{|l|}{ Duration of diabetes } \\
\hline before seroconversion (years) & 15 & 23 & 14 \\
\hline Peak BMI $\left(\mathrm{kg} / \mathrm{m}^{2}\right)$ & 28.3 & 24.6 & 28.5 \\
\hline Family history of diabetes & + & + & + \\
\hline \multicolumn{4}{|l|}{ Diabetic complications } \\
\hline neuropathy & + & + & + \\
\hline retinopathy & SDR & SDR & SDR \\
\hline nephropathy & - & microalbuminuria & - \\
\hline \multicolumn{4}{|l|}{ Islet-associated antibodies } \\
\hline ICA & $<1: 5$ & $<1: 5$ & $1: 20$ \\
\hline GADAb (U/ml) & $<0.4$ & 6890.0 & 956.0 \\
\hline $\mathbf{I A}-2 \mathrm{Ab}(\mathrm{U} / \mathrm{ml})$ & 31.0 & $<0.4$ & $<0.4$ \\
\hline \multicolumn{4}{|c|}{$\begin{array}{l}\text { Table } 2 \text {. Cases in which autoantibody seroconversion was seen after } 14 \text { to } 23 \text { years } \\
\text { of disease duration of type } 2 \text { diabetes are shown. In all cases, of the three autoanti- } \\
\text { bodies, } 1 \text { or } 2 \text { were seroconverted in patients who had well-established type } 2 \text { diabetes, } \\
\text { and who were complicated with microangiopathy. Abbreviation: SDR: simple diabetic } \\
\text { retinopathy }\end{array}$} \\
\hline
\end{tabular}

with diabetes at the age of 66 years and had been treated with sulfonylurea since the age of 69 . At admission in March 1997 (age: 79) ICA, GADAb, and IA-2Ab were negative, blood C-peptide was preserved. Until November 1997, HbA1c remained under $7 \%$ with $0.9 \mathrm{mg}$ voglibose and $60 \mathrm{mg}$ gliclazide, but from January 1998, glycemic control deteriorated. She was therefore readmitted to the hospital in May 1998 (age: 80). On admission, HbAic was $11.4 \%$ and GADAb had become positive $(956.0 \mathrm{U} / \mathrm{ml})$, and the plasma C-peptide levels were decreased. The oral agents were switched to premixed human insulin.

The three patients of Case 1, Case 2, and Fujita's case had 14 to 23 years' history of diabetes, and had been taking sulfonylurea as type 2 diabetic therapy for a long period of time. They originally had preserved insulin secretion, and of the established four islet-associated autoantibodies, including ICA, GADAb, IA-2Ab and insulin autoantibody (IAA), ICA, GADAb and IA-2Ab were initially all negative (IAA was not tested). In these three patients, secondary sulfonylurea failure occurred rapidly, and insulin secretory capacity was either reduced or exhausted, and as a result, multiple insulin injection therapy was required after seroconversions of autoantibodies were recognized. When Case 1 was initially admitted, worsening glycemic control was believed to be due to irregular lifestyle habits, and at that time autoantibodies were negative. Although insulin secretory capacity was slightly decreased, this phenomenon is often seen in the disease course of type 2 diabetic patients. Thereafter, his HbA1c increased rapidly, and localized insulin allergy developed. The relationship between insulin allergy and the onset of type 1 diabetes could not be clarified. In Case 2 insulin therapy was commenced 4 years previously because of secondary sulfonylurea failure. At that time, autoantibodies were negative. However, at the second hospitalization, exhausted insulin secretory capacity and appearance of
GADAb were confirmed. In Fujita's case, during 4 months including the holiday season, HbAlc rapidly increased from 6.9 to $11.4 \%$. The patient's physician thought that this poor glycemia was caused by high-calorie diet, but type 1 diabetes was confirmed on post admission tests. All 3 patients lacked obvious triggers for the onset of type 1 diabetes, including viral infection. A clinical summary of the cases at the development of type 1 diabetes mellitus is shown in Table 2, and clinical characteristics seen in common in the present patients are summarized in Table 3 .

Because there is no commercially available kit for IAA measurement in Japan now, IAA was not checked in any of the patients of us. A recent study showed that the pancreatic target epitope of $\beta$-cell damage in type 1 diabetes is autologous insulin (5), and as a result, IAA, autoantibody against autologous insulin, is attracting further attention. However, the sensitivity and specificity of the test for IAA are lower than those for the other islet-associated autoantibodies (6), and therefore the usefulness of IAA as a screening tool for type 1 diabetes is somewhat low.

Although type 1 and type 2 diabetes have been considered to be independent diseases, Kuzuya and colleagues (7) pointed out that some people could have genetic susceptibilities to both types of diabetes. Moreover, McDevitt recently proposed the possibility of genetic overlap for the two types of diabetes (8). A case reported by Shigihara and colleagues (9) had a similar clinical course to our cases presented here, but we have found few cases like ours in the literature.

Latent autoimmune diabetes in adults (LADA) may resemble "type 1 on type 2 " diabetes in terms of pathological features $(10,11)$. While LADA has a phenotype like adult type 2 diabetes, islet-associated autoantibodies are positive at the diagnosis of diabetes, and this type of diabetes is seen in up to $10 \%$ of type 2 diabetic patients. In these patients, 
Table 3. Characteristics Seen in Common in Cases Presented

\author{
1) Type 2 diabetes mellitus was initially diagnosed. \\ 2) Phenotype of type 2 diabetes was evident from onset. \\ 3) Islet-associated antibodies were originally all negative, and endogenous insulin secretion \\ was initially preserved. \\ 4) At 10 years or more after diagnosis of diabetes, spontaneous seroconversion of at least one \\ autoantibody occurred. \\ 5) Insulin secretory capacity progressively decreased, and fell to the level seen in an ordinary \\ type 1 diabetes mellitus in 3 months to 3 years. \\ 6) HLA serotype and genotype were consistent with those seen in Japanese type 1 diabetic \\ patients. \\ 7) Environmental factors triggering onset of type 1 diabetes remain unclear, but overeating or \\ insulin allergy may have been associated.
}

pancreatic $\beta$-cell failure is seen in about 5 years. Fourlanos and colleagues (11) stated that the autoimmune pathology of LADA was not "latent" and autoimmunity was a requirement for the diagnosis. In the present three patients, isletassociated autoantibodies were initially negative, and insulin secretory capacity was preserved; therefore, our cases were not LADA. Kobayashi and colleagues (12) described a subtype of type 1 diabetes of slowly progressive insulindependent diabetes mellitus (SPIDDM), which expresses a similar disease entity to LADA. SPIDDM is clinically type 2 diabetes at diagnosis, however, positive for islet-associated antibodies from the first, and eventually developed to the stage of insulin dependency. In the cases presented absence of autoantibodies was confirmed before decreased endocrine insulin, therefore our cases were also not SPIDDM. LandinOlsson and colleagues (13) examined patients who were first diagnosed with diabetes at ages 14 to 35 years and reported that even when ICA and GADAb were negative at diagnosis, some patients had converted to positivity one year later. They also found that C-peptide levels were low from the start in such patients, and they concluded that their patients had genuine type 1 diabetes. As to the reason for the delayed appearance of autoantibodies, the test sensitivity and preceding cellular immunity were discussed. Therefore, in Landin-Olsson's cases, autoimmunity was involved at the onset of diabetes, and their cases could be explained by a theory that they had type 1A (autoimmune) diabetes mellitus from the first. Therefore, our cases are different from the "genuine" type 1 diabetes described by Landin-Olsson, and we find it difficult to explain the long clinical course of our three patients as being due to a single type of diabetes, and speculate that type 2 diabetes can predate type 1 diabetes in individuals who have susceptibilities to both types of disease (7), or who have some common genes controlling disease sensitivity for both types of diabetes (14).

Consequently, it is debatable whether the first half of the disease course of our patients was that of type 2 diabetes, and this point cannot be clarified in the absence of strict diagnostic standards for type 2 diabetes. However, from the facts that any of the three patients was once obese, and had family history of diabetes, their insulin secretions were preserved for a long time, and islet-associated autoantibodies were initially negative, it is highly likely that these three patients had type 2 diabetes.

All three patients exhibited the HLA pattern characteristic of Japanese type 1 diabetes patients, thus supporting the onset of type 1 diabetes. According to an epidemiological study conducted in Finland, type 2 diabetes occasionally exhibits the HLA haplotype associated with type 1 diabetes (15). Moreover, in recent years, evidence for genetic overlap between types 1 diabetes and 2 diabetes has been found (16). These findings suggest the possibility that type 1 and type 2 diabetes are not separate entities but partially overlap, and that they share some common genes related to sensitivity and onset. Hence, it is possible that some patients develop these two types of diabetes at different times, as the present cases demonstrated.

This raises the question of what the trigger factor was for the seroconversion of type 1 diabetes-associated autoantibodies during the course of type 2 diabetes and the phenotypic progression to type 1 diabetes. In many cases, type 1 diabetes occurs acutely or subacutely, and environmental factors triggering the onset are rarely identified (1). The present patients did not recount episodes such as viral infection that might have triggered type 1 diabetes. McDevitt (8) stated that up to $10 \%$ of patients with type 2 diabetes have several characteristics that are usually seen only in type 1 diabetes, including very low C-peptide, positive autoantibodies, or early development of insulin therapy, but it is unclear whether this is simple coincidence of the two diseases or whether there is some real interaction between type 2 and type 1 diabetes. Furthermore, McDevitt said that up to $20 \%$ of the general population display an aspartate defect at HLA DQ $\beta 57$, which indicates potential sensitivity to type 1 diabetes. Despite this, only $0.5-0.8 \%$ of the population develop type 1 diabetes (8). This indicates that the onset of type 1 diabetes involves not only disease susceptibility, but also environmental factors. In this regard, McDevitt suggested that, 
in type 2 diabetic patients with susceptibility to type 1 diabetes in the HLA region, the additional stress (excessive insulin demand due to the presence of type 2 diabetes) on pancreatic $\beta$-cells can lead to autoantibody production, insulitis, and then insulin exhaustion (8). Then, type 1 diabetes is a multi-factorial disease that involves genetic as well as environmental factors.

With regard to the above-mentioned factors, in the present patients, who had a HLA class II genotype (DRB1-DQB1) characteristic of Japanese type 1 diabetes, the pancreatic $\beta$ cells were subjected to long-term and continuous stress due to the presence of type 2 diabetes. Finally, autoimmune processes against the pancreatic islets were induced, in Case 1 in association with insulin allergy, and in Fujita's case by the effect of excessive energy intake, an environmental factor. The details on the immunological mechanisms leading to insulitis or apoptosis in $\beta$-cells should be further explored. And it will be necessary to ascertain the mechanism of concurrent type 1 and 2 diabetes and to search for the relevant disease-causing genes (17).

From the above findings, it is concluded that autoimmune type 1 diabetes may be superimposed on well-established type 2 diabetes. Although co-occurrence of type 1 and type 2 diabetes is rarely seen, it is supposed that the incidence of type 1 diabetes among type 2 diabetic patients is much higher than that in the general population. This indicates that even in middle-aged or elderly patients who have had type 2 diabetes for a long period, it is necessary to consider the onset of type 1 diabetes in cases that develop acute or subacute secondary sulfonylurea failure, or progressively decreasing insulin secretion.

\section{References}

1. The Expert Committee on the Diagnosis and Classification of Diabetes Mellitus. Report of the Expert Committee on the Diagnosis and Classification of Diabetes Mellitus. Diabetes Care 20: 11831197, 1997.

2. Fujita M, Takahashi K, Murakami N, Yokota T. A case of type 1 diabetes mellitus in an aged patient after 14 years of non-insulin dependent type 2 diabetes. J Japan Diab Soc 43: 803-808, 2000 (in Japanese, Abstract in English).

3. Irvine WJ. Immunological aspects of diabetes mellitus: a review including the salient points of the NDDG report on the classification of diabetes. Immunology of Diabetes. Irvine WJ, Ed. Teviot Scientific Publications, Edinburgh, 1980: 1-53.

4. Takahashi K, Tasaka H, Hasegawa Y. Sensitivity and specificity for detection of islet cell cytoplasmic antibodies using rat pancreatic sections. Jpn J Clin Immun 18: 188-196, 1995 (in Japanese, Abstract in English).

5. Nakayama M, Abiru N, Moriyama H, et al. Prime role for an insulin epitope in the development of type 1 diabetes in NOD mice. Nature 43: 220-223, 2005.

6. Bingley PJ, Bonifacio E, Mueller PW. Diabetes antibody standardization program: First assay proficiency evaluation. Diabetes 52: 1128-1136, 2003.

7. Kuzuya T, Matsuda A. Classification of diabetes on the basis of etiology versus degree of insulin deficiency. Diabetes Care 20: 219-220, 1997.

8. McDevitt HO. Characteristics of autoimmunity in type 1 diabetes and type 1.5 overlap with type 2 diabetes. Diabetes 54(supple.2): S4-S10, 2005.

9. Shigihara T, Shimada A, Saisho Y, Kawai T, Maruyama H, Saruta
T. Seroconversion of GAD antibody in "unclassified" diabetes with long duration of diabetes. Diabetes Care 27: 1836-1837, 2004.

10. Zimmet PZ, Tuomi T, Mackay IR, et al. Latent autoimmune diabetes mellitus in adult (LADA): the role of antibodies to glutamic acid decarboxylase in diagnosis and prediction of insulin dependency. Diabet Med 11: 299-303, 1994.

11. Fourlanos S, Dotta F, Greenbaum CJ, et al. Latent autoimmune diabetes in adults (LADA) should be less latent. Diabetologia 48 : 2206-2212, 2005.

12. Kobayashi $T$, Tamemoto $K$, Nakanishi $K$, et al. Immunogenetic and clinical charasterization of slowly progressive IDDM. Diabetes Care 16: 780-788, 1993.

13. Landin-Olsson M, Arnqvist HJ, Blohme G, et al. Appearance of islet cell autoantibodies after clinical diagnosis of diabetes mellitus. Autoimmunity 29: 57-63, 1999.

14. Rich SS, Panter SS, Goetz FC, Hedlund B, Barbosa J. Shared genetic susceptibility of type 1 (insulin-dependent) and type 2 (noninsulin-dependent) diabetes mellitus: contributions of HLA and haptoglobin. Diabetologia 34: 350-355, 1991.

15. Tuomiletho-Wolf E, Tuomiletho J, Hitman GA, et al. Genetic susceptibility to non-insulin dependent diabetes mellitus and glucose intolerance are located in HLA region. BMJ 307: 155-159, 1993.

16. Leiter EH, Lee C-H. Mouse models and the genetics of diabetes: Is there evidence for genetic overlap between type 1 and type 2 diabetes? Diabetes 54(supple.2): S151-S158, 2005.

17. Tuomi T. Type 1 and type 2 diabetes: What do they have common? Diabetes 54(supple.2): S40-S45, 2005.

(C) 2007 The Japanese Society of Internal Medicine http://www.naika.or.jp/imindex.html 